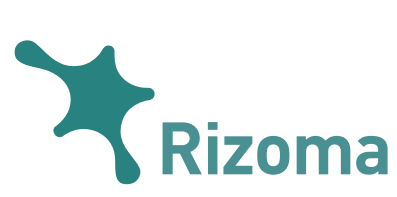

\title{
Dupla personalidade?
}

\section{Estrutura narrativa de Broad City na internet e na televisão}

Resumo: A ficção remete a certa oposição à realidade, em contrapartida, Patrícia Azambuja' prescinde aspectos de verossimilhança para se fazer reconhecível. O quanto de distinção e semelhança as diferentes estruturas narrativas evocam é a questão central neste trabalho, que incorpora como metodologia exploratória a decupagem destes aspectos em Broad City, tanto na sua versão para WEB quanto para TV: foco narrativo, caracterização das personagens, espaço, tempo e, inevitavelmente, recursos estéticos utilizados nas cenas.

Palavras-chave: Ficção. Estrutura narrativa. Websérie. Sitcom.

\section{¿Doble personalidad? Estructura narrativa de Broad City en Internet y en la televisión}

\footnotetext{
${ }^{1}$ Doutora em Psicologia Social pela UERJ, mestre em Artes Visuais pela UNESP e pesquisadora vinculada ao Observatório de Experiências Expandidas em Comunicação ObEEC/ UFMA. Autora do livro Televisão Híbrida: recepção de TV sob a perspectiva sociotécnica da Teoria Ator-rede, também coordenou o projeto de pesquisa Comunicação Expandida II (Financiamento FAPEMA).
}

Resumen: La ficción remite a cierta oposición a la realidad, en cambio, prescinde aspectos de verosimilitud para hacerse reconocible. Lo que de distinción y semejanza las diferentes estructuras narrativas evocan es la cuestión central en este trabajo, que incorpora como metodología exploratoria la decupación de estos aspectos en Broad City, en su versión para WEB y para TV: foco narrativo, caracterización de los personajes, espacio, tiempo e, inevitablemente, recursos estéticos utilizados en las escenas.

Palabras clave: Ficción. Estructura narrativa. Serie web. Comedia de enredo.

\section{Double personality? Narrative structure of Broad City on the Internet and on Television}

\begin{abstract}
The fiction refers to a certain opposition to the reality, in contrast, it dispenses aspects of verisimilitude to make itself recognizable. How much of distinction and similarity the different narrative structures evoke is the central question in this article, which incorporates as exploratory methodology the analysis of these aspects in Broad City, both in its version:WEB/TV: narrative focus, characterization of the characters, space, time and inevitably, aesthetic features used in the scenes.
\end{abstract}

Keywords: Fiction. Narrative structure. Web series. Sitcom. 


\section{Y.izoma}

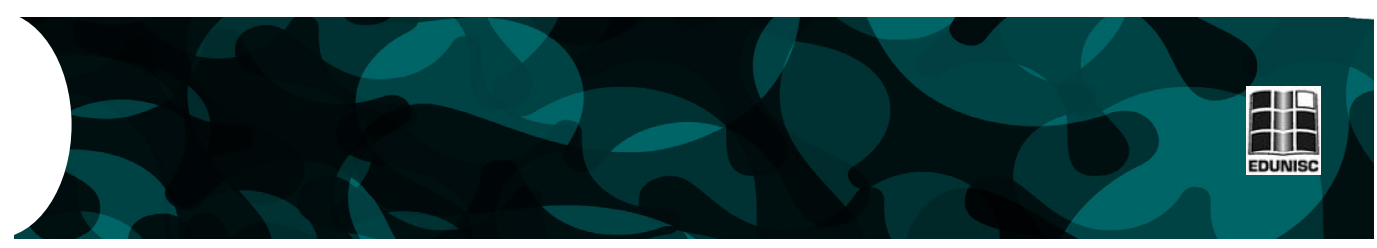

\section{Introdução}

A partir de uma noção fenomenológica de como se dá a apreensão do mundo pelo ser humano, Santaella (2005) discorre sobre a diversidade do universo sensível e suas conversões possíveis em realidades inteligíveis. A pesquisadora afirma que através de diferentes combinações entre três matrizes de linguagem - verbal, visual e sonora - constituem-se todos os outros processos sígnicos instituídos pelo ser humano. Com a variabilidade das ferramentas comunicacionais, passa a ser uma questão central para a mediação: compreender fusões e combinações possíveis entre essas matrizes essenciais. “As linguagem são muitas" (SANTAELLA, 2005, p. 28), e ampliam-se ao longo das revoluções - industrial, eletrônica e informática - ampliando o poder multiplicador da linguagem. "A era das imagens de registro físico de fragmentos do mundo, iniciada com a fotografia e seguida pelo cinema, TV, vídeo [...] tem apenas um século e meio de existência e já estamos instalados agora em plena efervescência da era pós-fotográfica" (SANTAELLA, 2005, p. 28). A autora propõe demonstrar algumas bases lógicas para regência dessas combinações e, nesse sentido, conclui que os "processos de hibridização atuam como propulsores para o crescimentos das linguagens" (SANTAELLA, 2005, p. 28), pois a teoria dos signos de Charles Pierce não segue apenas a noção de signo genuíno, mas a mistura dentro dos sistemas semióticos.

Com base na informática e sua prerrogativa convergente - ou por seu poder de síntese entre meios - o híbrido reafirma a ideia de superposição de novos arranjos, num espaço de múltiplas imagens, vozes e textos. Calabrese (1987), Machado (2007), Bentes (2007), entre outros, discorrem sobre essa escritura complexa, a partir da qual propõem-se múltiplas apreensões: pela saturação, pelo excesso, pela instabilidade, mas essencialmente pela recusa de formas unitárias de expressão e de produção no universo da cultura. A hipermídia, por exemplo, aponta "para a possibilidade de uma nova 'gramática' dos meios audiovisuais e também para a necessidade de novos parâmetros de leitura por parte do sujeito receptor" (MACHADO, 2007, p.75).

Parte-se, para efeitos deste trabalho, da percepção do híbrido como base para o entendimento de algumas transformações percebidas na gramática de produtos ficcionais televisivos, tanto os que transitam pelo televisor "convencional", como os compartilhados via aplicativos live streaming ou sites de vídeo on demand (VOD).

\section{Broad City: ficção, verossimilhança e empatia}

O termo ficção, normalmente, ligado à ideia de fantasia, sonho, oposição ao empírico e palpável, também envolve controvérsias ao propor formas de expressão que, em muitos casos, colocam no mesmo patamar ficcionalidade e factualidade. Bulhões (2009) pondera inclusive que vivemos duas vidas: de um lado a real, na qual realizamos atividades úteis e práticas, e de outro, a ficcional, da imaginação e do devaneio. "Diante de tal oposição, 
seria o caso de se admitir que aturaríamos a 'primeira vida' para termos, como se fosse uma recompensa, a segunda" (BULHÕES, 2009, p. 21). Tal proposição coloca em evidência, para esse complexo mundo da ficção nas mídias, certos atributos também de fusão entre realidade e fantasia.

No entanto, para o próprio Bulhões (2009), apesar de modalidades narrativas mais recentes trazerem formas de fruição bastante inovadoras, persistem atributos históricos comuns, que são: 1) imagens renovam e estimulam nosso imaginário; 2) respeito às particularidades do universo das mídias sem deixar de lado as contribuições da teoria narrativa da literatura. Desse modo, o pesquisador vincula as principais categorias também dirigidas ao ficcional midiático: foco narrativo, personagem, espaço e tempo.

Visando a compreender as diferentes gramáticas, suas aproximações e distanciamentos, ou mesmo combinações entre as categorias narrativas, este artigo propõe analisar em especial aspectos de convergência entre os elementos de caracterização da ficção seriada, utilizando como metodologia exploratória a decomposição comparativa da estrutura narrativa em Broad City. O interesse pela temática surge a partir da constatação de particularidades neste produto - que surge no Youtube de forma independente, entre $2010 \mathrm{e}$ 2011, como uma websérie de teor cômico e, após conquistar seu público específico, além dos olhares da crítica norte-americana, ganha espaço na TV, pelo canal Comedy Central, no ano de 2014.

Criada por Abbi Jacobson e Ilana Glazer, Broad City tem como storyline principal a mesma história-base nas duas versões e narra os encontros e os desencontros de duas amigas de vinte e poucos anos que moram em Nova York. Elas passam por situações cômicas no dia a dia da cidade grande e, de acordo com entrevista feita para o site Vice $^{2}$, as criadoras usam alguns eventos que já aconteceram com elas e com conhecidos para escrever as histórias. Nesse caso, um dos destaques da série é a busca por aspectos de verossimilhança (combinação híbrida entre ficcionalidade e factualidade): com personagens que erram, andam de transporte público, não ganham muito dinheiro, não tem o corpo perfeito e se divertem com pouco.

Para as criadoras, a versão para a internet tinha o desafio de encontrar um público específico. Logo, Broad City alcançou em um primeiro momento os moradores de NYC, especialmente, aqueles que se identificavam com as experiências vividas pelas personagens, isto porque, Abbi e Ilana sempre estavam explorando o lugar de alguma forma, usando o metrô, andando pelas ruas, conversando em bares e vivendo situações típicas dos habitantes da cidade. A empatia entre websérie e público-alvo foi constatada quando as criadoras perceberam que a comunidade da comédia em Nova York dava respostas positivas, com críticas em sites e compartilhamento dos vídeos. O que talvez tenha sido o estopim para incorporação do modelo de negócios e migração para TV.

Apesar do distanciamento evidente entre os modelos de comercialização nos dois meios, parece-nos prioritário para este trabalho, compreender aspectos que envolvam as construções narrativas nas duas estruturas apresentadas. Em especial, o que caracteriza o formato para WEB que possa atrair a atenção de um canal de televisão.
2 Disponível em $<$ https://www.vice. com/read/we-spoke-to-broad-citys-abijacobson-and-ilana-glazer-190>. 

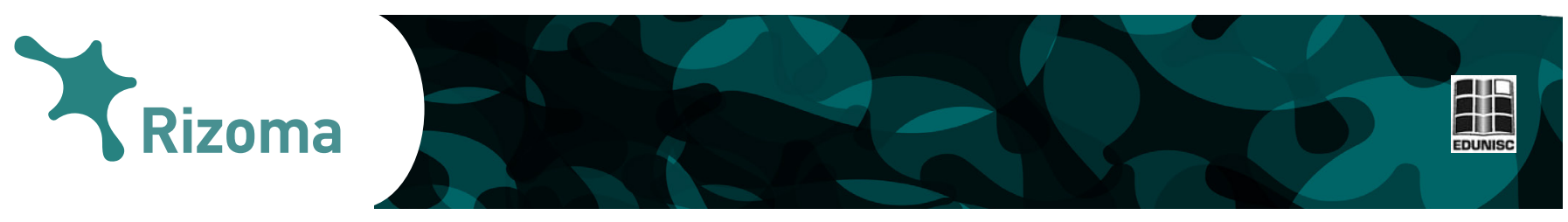

\section{Estrutura narrativa dos websódios no Youtube}

O foco narrativo em Broad City, isto é, a constatação da existência de um narrador, ou "uma instância responsável por revelar a nós, espectadores ou usuários, o mundo narrativo" (BULHÕES, 2009, p. 80) é a percepção de que a história está sendo contada por duas amigas, judias, solteiras, de vinte e poucos anos, que estão tentando organizar suas vidas em NYC. As duas enunciadoras do discurso assumem nitidamente a voz da narrativa, são entidades presentes na cena, e passam por situações cômicas no dia a dia da grande cidade, com as quais o espectador consegue se identificar em muitos momentos. Para Bulhões (2009, p. 82), "o ato de inventar histórias é inseparável da invenção das formas de narrá-las". Assim, Abbi e Ilana geram empatia junto aos webespectadores mostrando e narrando - apesar de que o "mundo ficcional das mídias está centrado no mostrar, não no narrar" (BULHÕES, 2009, p. 81).

Através de recurso de zoom, da câmera na mão, gravações pela webcam, com poucos recursos tecnológicos, figurinos simples, sem maquiagem, cenários com quase nenhuma produção (nas ruas ou na casa das duas), praticando atividades típicas da cidade grande e conversando sobre os mais variados assuntos, em certo sentido, as protagonistas dão o tom intimista necessário para ambientação de suas experiências diárias, assim como aspectos de sua personalidade: Abbi é metódica, desajeitada, muito otimista, organizada e procura sempre fazer tudo de maneira correta; já Ilana é extrovertida, não se preocupa com o que os outros pensam, bem-humorada, disposta a se divertir a qualquer momento e a mais desapegada nas relações pessoais. As duas são as únicas personagens fixas da websérie, que estão presentes em todos os websódios. Apesar de não haver personagens secundários regulares, outros personagens participam, mas não têm seus nomes identificados.

Os websódios de Broad City possuem começo, meio e fim (no tempo máximo de oito minu- tos cada) - uma situação de um dia na vida delas - e tem apenas uma temática, tornando-se histórias autônomas, apesar de seguirem a storyline central do produto audiovisual. A websérie não explora aspectos de continuidade no contexto das narrativas específicas, desse modo, os episódios podem ser vistos de forma aleatória. $\mathrm{O}$ webespectador compreenderá, se já tiver incorporado a história-base principal.

A verossimilhança necessária a esse tipo de representação está registrada especialmente nos aspectos que articulam as experiências dessas personagens, "uma vez que o verossímil não está circunscrito à verdade, ao que ocorreu de fato, mas diz respeito ao que poderia acontecer, ao possível" (BULHÕES, 2009, p. 31). Abbi e Ilana, atrizes e amigas na vida real, são moradoras de bairro descolado em Nova York. Afirmam que nunca pretenderam tornar os vídeos virais (atingindo indiscriminadamente um grande número de visualizações), mas sim priorizar mais a qualidade dos webespectadores, através das estratégias de reconhecimento e empatia com as histórias.

Além do conceito geral e das personagens como elementos centrais da narrativa, outros aspectos também delimitam essa história: o espaço, como o 


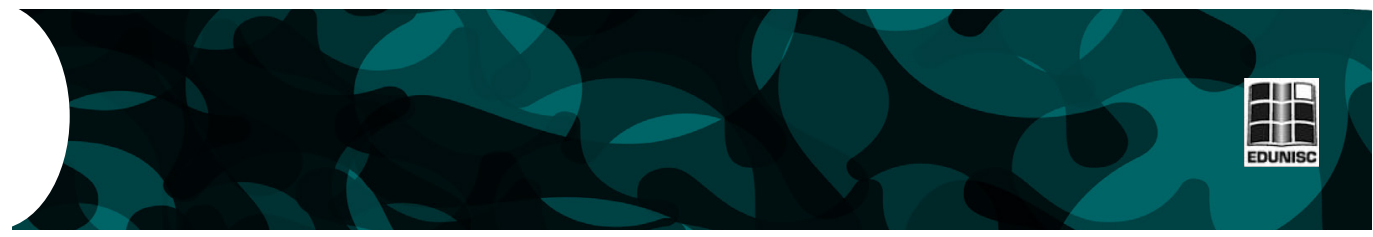

"componente físico que serve de cenário ao desenrolar da ação" (BULHÕES, 2009, p. 88); e o tempo, "categoria que está na essência da narratividade [pois] a imagem em movimento promove uma experiência visual da própria fluidez temporal" (BULHÕES, 2009, p. 93). A sucessão de planos na websérie segue, como já foi dito, uma linha menos comprometida com aspectos clássicos, incorporando, portanto, experiências concretas das duas personagens através de um formato moldado para este fim: direção de fotografia também intimista da câmera na mão, sem muitos recursos e "pouca interferência" nos espaços ou objetos de cena (FIGURA 1). O aqui e o agora da vida de Abbi e Ilana são compostos pelos interiores das casas das próprias atrizes ou pelos espaços abertos da cidade de Nova York: Central Park, metrô e os bairros do Brooklyn e Manhattan. Na concepção de Rodrigues (2014), o lugar e os cenários são essenciais para criar um mundo inconfundível e trazer verossimilhança à narrativa, produzindo identificação com o espectador, que por consequência se reconhece naqueles espaços, assim como nas histórias vividas pelas personagens.

Figura 1 - Cenas dos vídeos no Youtube, com destaque às locações na cidade de Nova York, fotografia menos estável e utilização da webcamonte: Printscreen produzido pelas autoras
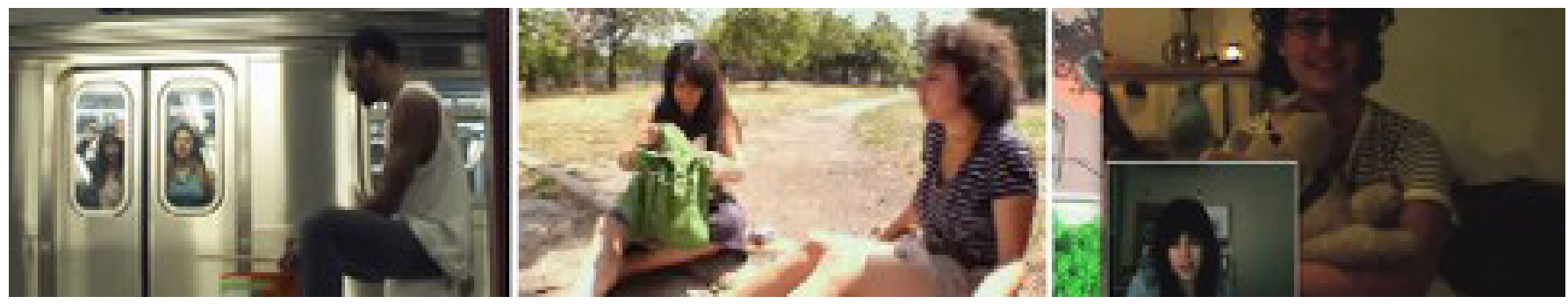

Zanetti (2013) discorre sobre essa estética intimista e simples das narrativas seriadas em ambientes virtuais, circunscrita no contexto das produções independentes, com poucos recursos financeiros, que efetiva gêneros conhecidos como confessionais na WEB (SIBILIA, 2008), entre eles "os vlogs, fotologs, vídeos caseiros - caracterizados por uma estética amadora e basicamente associado à figura do internauta como personagem de si mesmo" (ZANETTI, 2013, p. 79). Ainda existem webséries com essa concepção. No entanto, o cenário vem mudando. Aeraphe (2013), professor e realizador na área, afirma que na internet observa-se uma quantidade diversificada de conteúdo, das celebridades instantâneas, passando pelas produções de qualidade duvidosa ao conteúdo premium - capaz de prender a atenção do público e consolidar modelos de negócios mais estáveis.

A presença de webséries super produzidas é cada vez maior. Muitas são realizadas por profissionais, grandes produtoras ou por pessoas com bons equipamentos e excelentes ideias. Elas são consideradas, também no campo do audiovisual, como maior possibilidade de experimentação, pois os idealizadores possuem grande liberdade criativa e podem avaliar o sucesso dos seus conteúdos diretamente com o público, pelo número de visualizações e comentários. 

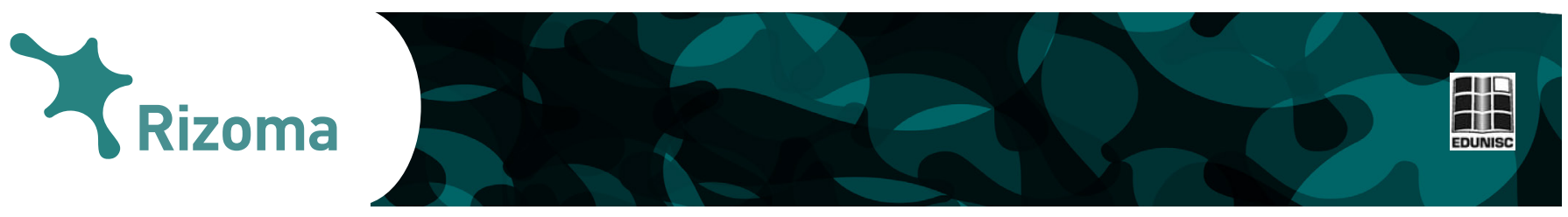

\section{Alguns websódios: desenho da cena}

Existem alguns pontos recorrentes nas narrativas dos websódios das temporadas de Broad City. Conforme já citado, as duas protagonistas têm personalidades bastante diferentes e isto é explorado na websérie de maneira evidente. O websódio The Commute é um dos que deixa isto mais claro, quando mostra como as personagens acordam e agem antes de ir ao trabalho. Este websódio também transmite uma das principais características de Broad City: a amizade de Abbi e Ilana. Ele é cheio de pequenas cenas intercaladas, demonstrando a rotina das duas pela manhã. Enquanto Abbi acorda cedo, se exercita e passa produtos em seu rosto, Ilana tem dificuldade para acordar e parece desmotivada. Simultaneamente, Abbi escolhe com calma roupas do seu guarda roupa e Ilana pega a primeira que encontra (FIGURA 2). A trilha sonora também é um elemento narrativo importante nesses vídeos. Nas cenas de Abbi, uma música romântica dos anos 80 é utilizada ao fundo; e nas cenas de Ilana, um rap contemporâneo. Quando Abbi e Ilana se encontram um pouco antes de chegar ao local dos seus trabalhos, as duas músicas, que são de estilos e gêneros diferentes, se juntam em uma, combinando como se fosse um mashup. Isto foi realizado para representar a união e a amizade das duas amigas, que têm personalidades opostas; mas também são pequenos recursos para demonstrar características marcantes das mesmas, e moldar a narrativa como um todo.

Figura 2 Cenas dos vídeos no Youtube, com destaque de cenas do websódio The Commute
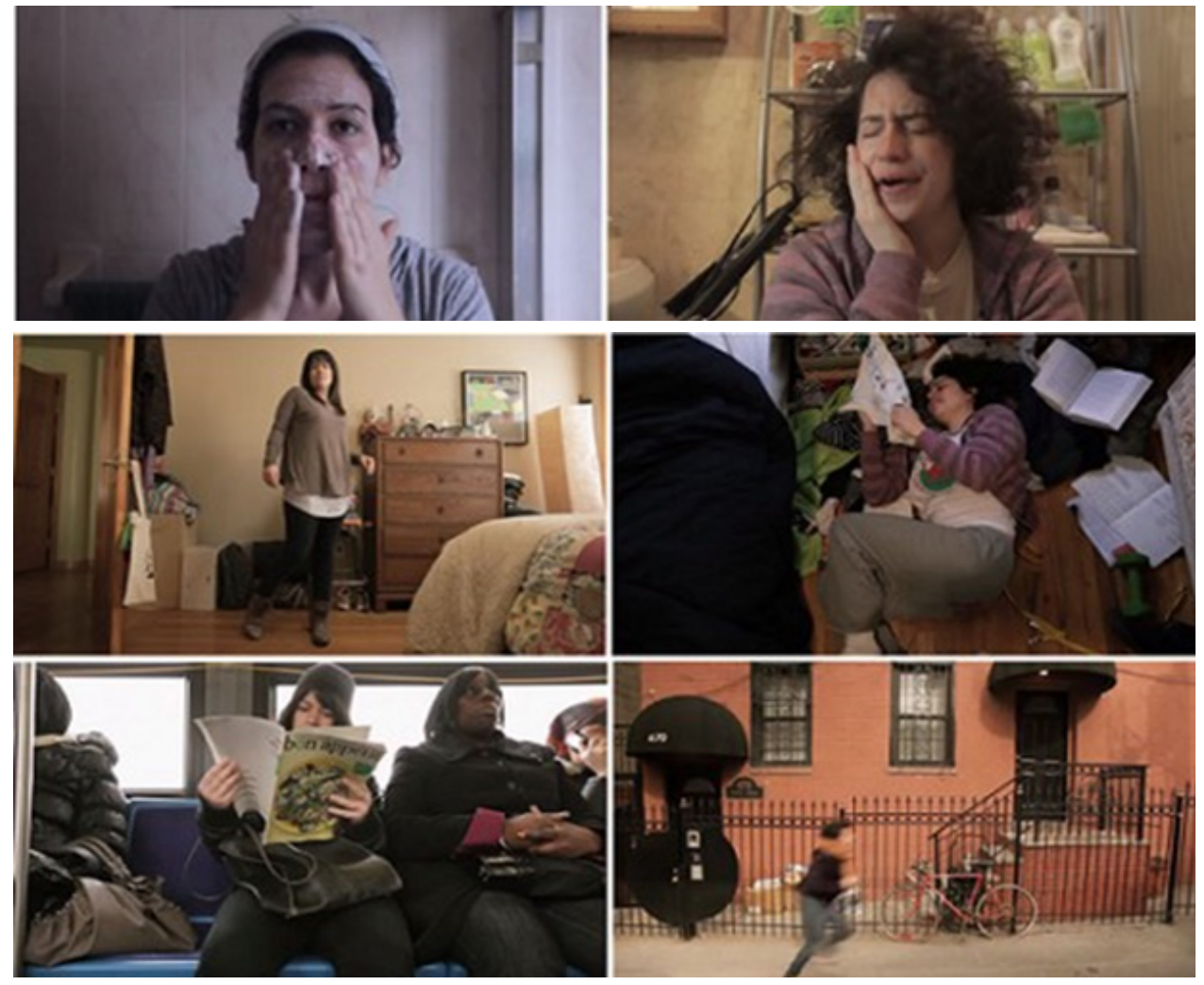

Fonte: Printscreen produzido pelas autoras 
Em termos de etapas da narrativa, Rodrigues (2014) afirma que a construção das personagens e seus atributos está atrelada à maneira como são apresentadas as ações, subdividas ao ponto de desencadear novas. $\mathrm{O}$ folhetim, como embrião da narrativa seriada, predispõe uma composição por episódios, organizando tramas paralelas que "vão se multiplicando e funcionam como elementos de suspense, com ganchos que, ao mesmo tempo, desviam do módulo principal, mas aguçam a curiosidade a respeito das possíveis relações entre um enredo e o(s) outro(s)" (RODRIGUES, 2014, p. 72). Nesse caso, Broad City feita para WEB, em suas duas temporadas, demonstra muita simplicidade em seus enredos, sempre autônomos e pouco fragmentados internamente.

As duas protagonistas não passam por uma jornada ou por grandes conflitos na busca por alcançar objetivos. Apesar de Abbi e Ilana possuírem personalidades singulares e marcantes - aspectos importantes para a conquista do público -, suas trajetórias não mudam ou passam por situações muito conflituosas. Obviamente, o fato dos websódios terem no máximo oito minutos contribuiu para que as histórias fossem menos complexas, mais autônomas e fechadas. Abbi Jacobson afirma, em entrevista ao FastCoCreate ${ }^{3}$, que os enredos eram direcionados por um recorte de mundo pouco estabelecido, no qual apenas apresentavam-se aspectos e vivências óbvias de duas personagens, com empregos sem futuro e que gastam muito tempo saindo, se divertindo e fazendo os outros rirem.

Talvez por esse potencial à maior complexidade, ou pela possibilidade de trabalhar episódios mais longos, as produtoras, a partir da segunda temporada, começaram a investir mais no projeto e tratá-lo como uma série de televisão. Contrataram uma empresária, abriram uma pequena produtora, começaram a pagar profissionais para filmar e editar os vídeos. Escreviam sobre Broad City em blogs especializados, promoviam nas redes sociais e colocavam vídeos adicionais no canal do Youtube. Jacobson e Glazer explicam em entrevista ${ }^{4}$ que o processo de aprendizagem em torno das possibilidades de promoção do trabalho (contato com editores, produção de artigos, garimpagem de likes etc.) foi lento, mas constante, e de fundamental importância para o sucesso do trabalho.

Tais estratégias comerciais amparam-se na exploração de aspectos comportamentais da cultura da participação (SHIRKY, 2011); assim como na emergência do conceito de fandom (HILLS, 2002; BOOTH, 2010; GRECO, 2015), que se destaca por suas ações ativas, e pela capacidade de se apropriar de conteúdos de seu interesse. "Serviços que nos ajudam a compartilhar coisas prosperam exatamente porque tornam mais fácil, e muitas vezes mais barato, fazer coisas que já gostávamos de fazer" (SHIRKY, 2011, p. 58). Brown (2014) discorre exatamente como o mundo conectado oferece acesso infinito às possibilidades ligadas ao entretenimento sobre a plataforma que você escolher - laptop, tablet ou telefone - e o momento de consumo. Esse novo fenômeno, na sua opinião, não é tão recente assim.

Com o fim da websérie em 2011, Jacobson e Glazer conseguiram um contrato com o Comedy Central. Atualmente, Broad City é uma sitcom do
3 Disponível no link: https://www.fastcocreate.com/3025672/how-the-creatorsof-broad-city-tur- ned-their-web-seriesinto-a-tv-show.

4 Disponível no link: http://www.npr. org/2015/01/14/377061731/in-broadcity-two- women-make-comedy-fromthe-muck-of-new-york-living. 

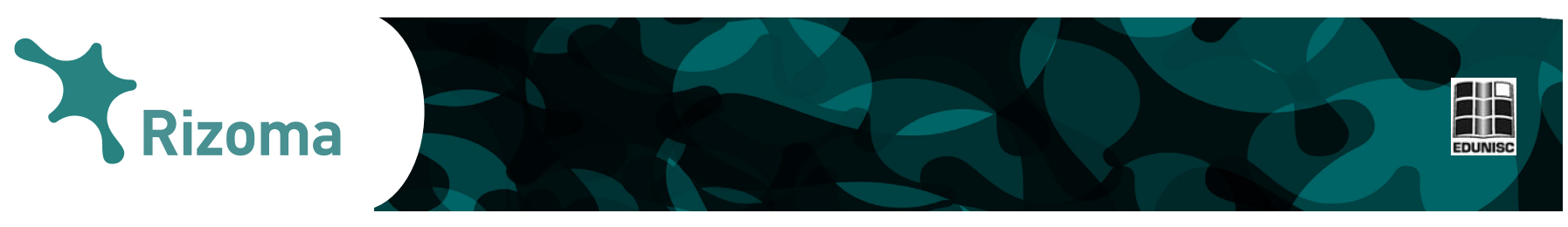

canal desde 2014 e estreou a quarta temporada em 2017. Para as criadoras, um dos maiores desafios na transição da internet para a televisão foi criar um universo mais amplo, com diversos arcos narrativos, mais detalhes nas ações/ conflitos e mais aprofundamento na construção das personagens.

\section{Estrutura narrativa da sitcom no canal Comedy Central}

Na televisão, a storyline de Broad City é similar à da websérie, as criadoras mantiveram o mesmo universo e as mesmas protagonistas. No entanto, deixaram clara a primeira diferença em relação à série na WEB: as duas personagens que antes só eram reconhecidas como Abbi e Ilana, na série de televisão possuem nome e sobrenome, são Abbi Abrams e Ilana Wexler.

Além disso, apesar de terem os mesmos traços de personalidade, alguns aspectos pessoais são incluídos nas profissões de cada uma: Abbi Abrams trabalha como zeladora na academia Soul- stice, mas deseja ser promovida ao cargo de treinadora, enquanto isto, alimenta o sonho de viver das ilustrações que produz em seu tempo livre; Ilana Wexler trabalha em uma empresa de vendas chamada Deals Deals Delas, por outro lado, não se importa com nada no emprego e raramente realiza suas atividades.

A série de televisão também possui vários personagens secundários e fixos que estão pre- sentes no universo das protagonistas e auxiliam no desenvolvimento das histórias de cada uma. Esses personagens ajudam na construção de histórias mais complexas, criando o universo da série e contribuindo para que os espectadores fiquem mais interessados em acompanhar cada episódio.

Para Pallottini (2012), os personagens da televisão são modificados e criados de acordo com os recursos próprios deste meio. Então, tudo que está à sua volta define suas características, como os cenários que os circundam, as roupas que eles vestem, as cores que são escolhidas e "todos os signos a serem lidos e decifrados pelo espectador" (PALLOTTINI, 2012, p. 126). Nesse sentido, destacam-se aqui, além das personalidades de Abbi Abrams e Ilana Wexler, aspectos de particularização material, tais como: figurinos e cenários.

O figurino (FIGURA 3), como parte essencial da caracterização das personagens, que antes era bem simples na websérie, na sitcom transmite as personalidades das protagonistas. Ilana costu- ma usar roupas mais coloridas, modernas, extravagantes e que mostram partes do corpo; já Abbi é discreta e utiliza roupas básicas na maioria das vezes com tons escuros ou pastel. Os objetos e o modo de organização da casa das protagonistas também ilustram a personalidade das duas. O quarto de Abbi, por exemplo, é organizado e todo decorado, já a casa de Ilana é bagunçada e com o aspecto de estar sempre suja. Essas questões relacionadas ao espaço ficam mais evidentes, e mais bem construídas, na sitcom, ao compararmos com a websérie. 

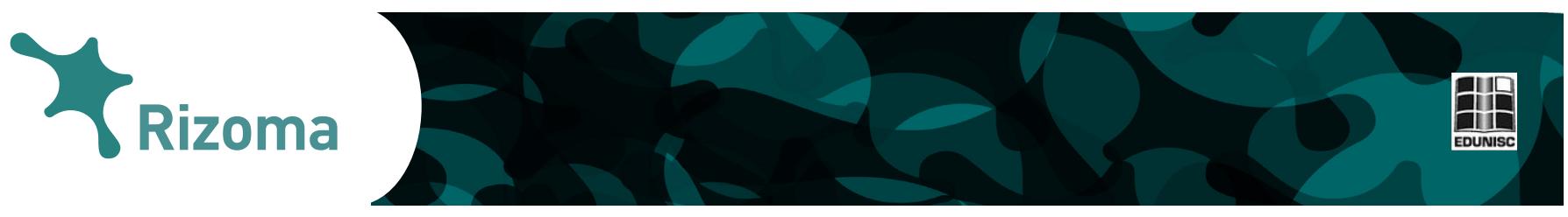

Figura 4 - Cenas dos episódios da sitcom, com destaque para os figurinos pontuando as diferenças entre as personalidades das duas
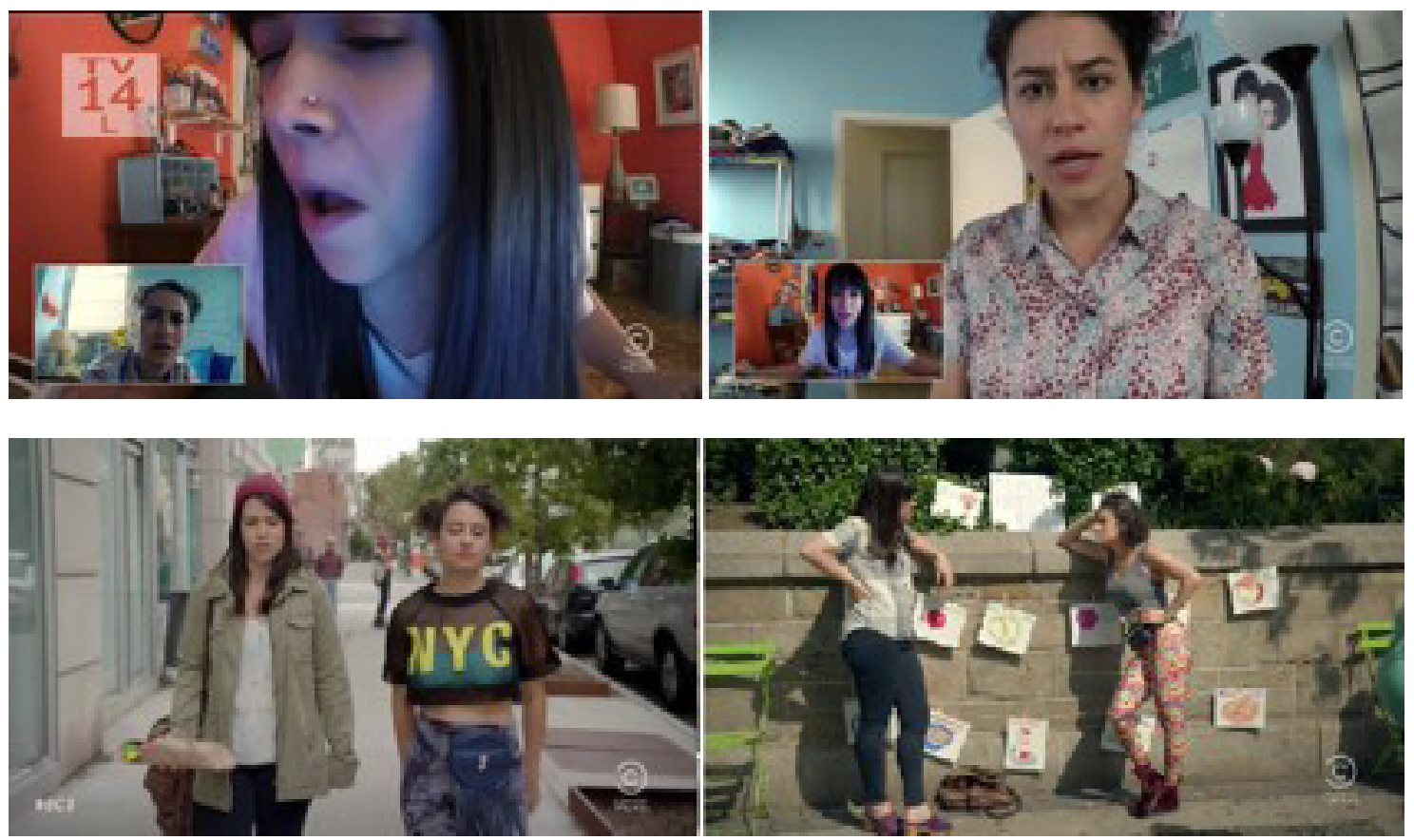

Fonte: Printscreen produzido pelas autoras

Em relação aos movimentos de câmera e enquadramentos, Broad City utiliza edições rápidas, com planos que não duram muito, e ousa neste aspecto, principalmente em comparação ao formato clássico das sitcons em geral. Estas características já demonstram a forte influência que a websérie trouxe para o produto na televisão, propondo novos padrões estéticos para esse gênero, que originalmente utiliza planos mais estáveis. Ainda em relação a essas influências, as personagens conversam muito uma com a outra pelo computador, fazendo uso da webcam - uma estratégia de fotografia bem comum na websérie (FIGURA 3).

Nessa comédia, os cenários mais utilizados (FIGURA 4) também são o interior das residências de Abbi e Ilana, os ambientes de trabalho delas e vários locais da cidade de Nova York. A ideia de mundo inconfundível, proposta por Rodrigues (2014), é preservada na versão para TV, inovando também em relação às sitcoms convencionais, que na maioria das vezes são gravadas em estúdios e locações fechadas. As garotas exploram o lugar constantemente e esta é inclusive uma das propostas do produto televisivo. Algumas dessas locações consistem em bairros do Brooklyn, metrôs, boates, ruas, parques, restaurantes ou bares da cidade e nas lojas preferidas das protagonistas: Bed e Bath \& Beyond. Enfim, elas utilizam a cidade para representar situações típicas dos nova-iorquinos. Em comparação à websérie, a série de TV explora ainda mais Nova York, o que abre em possibilidades para narrativas originais e criativas. 

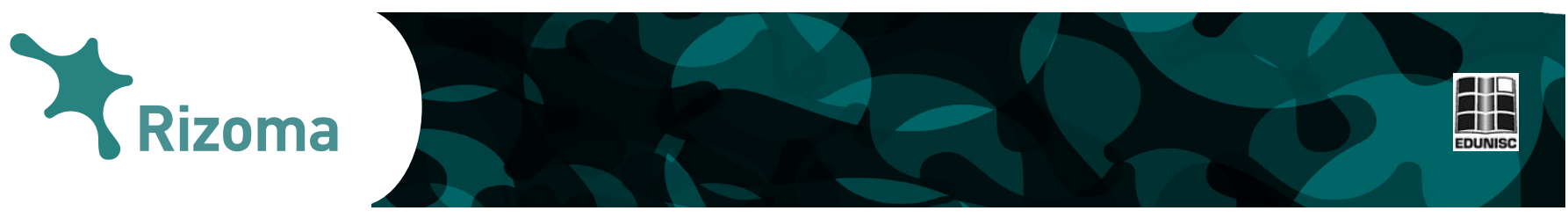

Figura 4 - Cenas dos episódios da sitcom, com destaque para locações externas nas ruas de Nova York, na loja Bed, Bath \& Beyond e os interiores das casas de Abbi e Ilana
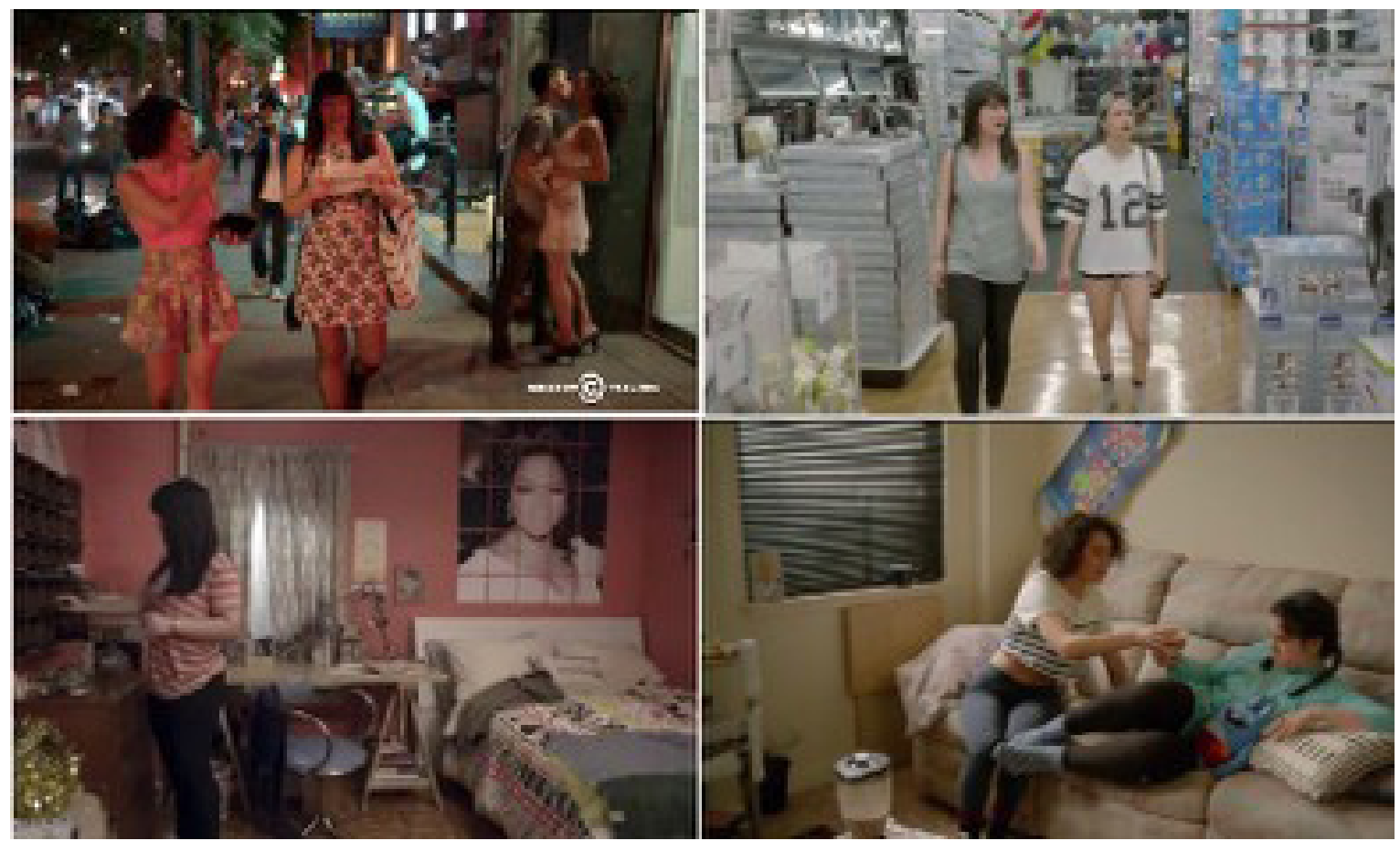

Fonte: Printscreen produzido pelas autoras

Como a produção televisiva possui recursos para variados cenários, diferente de quando era uma websérie de produção independente, existem inclusive episódios que se passam fora da cidade de Nova York. O sexto da terceira temporada (Philadelphia) é gravado na Filadélfia, lugar onde a personagem Abbi passa sua infância e adolescência. A possibilidade de gravar em outra cidade gera uma história diferente, a partir da qual elas vivenciam outros costumes e experiências.

Os enredos, de modo inevitável, tornam-se mais complexos, e na sitcom estão relacionados ao cotidiano e ao funcionamento das próprias cidades: a dificuldade com o transporte público, em conseguir uma mesa para sentar nos parques, filas que enfrentam para retirar documentos, ou mesmo a busca por diversão, o início da vida adulta e o dia a dia nos seus empregos.

\section{Easter eggs e tramas paralelas: complexidade narrativa}

No seriado, existem alguns elementos narrativos que são utilizados para captar ainda mais a atenção do espectador, como os easter eggs - mensagens ocultas que só os espectadores mais atentos conseguem perceber. Por exemplo, no primeiro episódio da segunda temporada (In Heat), Abbi e Ilana estão no metrô e uma idosa desconhecida chama Abbi pelo nome de Val, enquanto ela e os espectadores ficam sem entender. Mais adiante, no quinto episódio 
(Hashtag FOMO), descobrimos que Abbi, quando bebe demais, se apresenta como Val, faz performances em um bar escondido de Nova York, e quando fica sóbria não lembra de nada. Broad City também é cheia de piadas intencionais e referências que só os espectadores assíduos entendem.

Mesmo sendo uma série de comédia, as personagens evoluem e se envolvem em narrativas mais elaboradas durante as três temporadas, tanto na questão dos relacionamentos com outras pessoas, quanto nas questões profissionais. A personagem Abbi Abrams tem seus próprios conflitos e passa por arcos narrativos específicos dentro da storyline central. No âmbito do trabalho, ela procura o sucesso, tornar-se uma ilustradora reconhecida e também ser promovida na academia em que trabalha. Na vida amorosa, ela começa a série apaixonada pelo seu vizinho Jeremy, apesar de se relacionar com outras pessoas. Alguns desses objetivos de vida ela consegue alcançar, como quando finalmente é promovida para o cargo de treinadora na Soulstice ou quando consegue ficar com Jeremy no episódio Knockoffs. Aspectos amorosos da vida da personagem continuam a ser explorados em outras temporadas, culminando na relação com seu chefe Trey.

Um exemplo de crescimento nas histórias das protagonistas diz respeito também à Ilana Wexler, personagem muito confiante, de bem com a vida, que costumava sempre driblar suas responsabilidades e, até a segunda temporada, não tinha sofrido nenhuma grande consequência devido a isso. Porém, no episódio Game Over, a personagem é atingida por conflitos em sua trajetória: é dispensada de um trabalho extra por faltar seu turno e em seguida também de seu emprego na Deals Deals Deals. Outro fato marcante na história de Ilana é o fim do relacionamento casual que tinha com Lincoln. No oitavo episódio da terceira temporada (Burning Bridges), Lincoln decide terminar, deixando a personagem surpresa e também o próprio espectador que estava acostumado com este relacionamento não convencional. Ela fica visivelmente abalada, mesmo não querendo demonstrar, e é a primeira vez que a percebemos vulnerável na série. Nota-se que ela gostava do Lincoln de verdade, mesmo que do seu jeito. A Ilana sempre alegre e bem resolvida mostra-se frágil no decorrer do episódio. O espectador vê algo raro, a personagem triste e insegura. A história mostra que até ela pode se machucar e amadurecer com isso.

Burning Bridges é um episódio importante para analisar, pois além de mostrar a evolução das personagens e da relação entre elas até a terceira temporada, tem a premissa de traços dramáticos e narrativas paralelas. A história principal é a de Abbi, quando começa o episódio com o seu chefe Trey a convidando para um jantar romântico. Ela passa a maioria das cenas elaborando como vai agir no encontro, porque não quer dar a impressão de que deseja algo sério. Abbi também mente para a amiga Ilana sobre estar saindo com ele. Enquanto isso, ela vai ao seu apartamento e tenta escolher uma roupa para o encontro com Trey, com a ajuda de Bevers, um personagem que até pouco tempo ela repugnava e que agora demonstrava traços de cumplicidade. Pela definição Rodrigues (2014), esta seria a história $A$ por ser de uma das protagonistas e ter mais espaço dentro do episódio, já a história $B$ neste episódio é a de como Ilana reage ao término com Lincoln. 

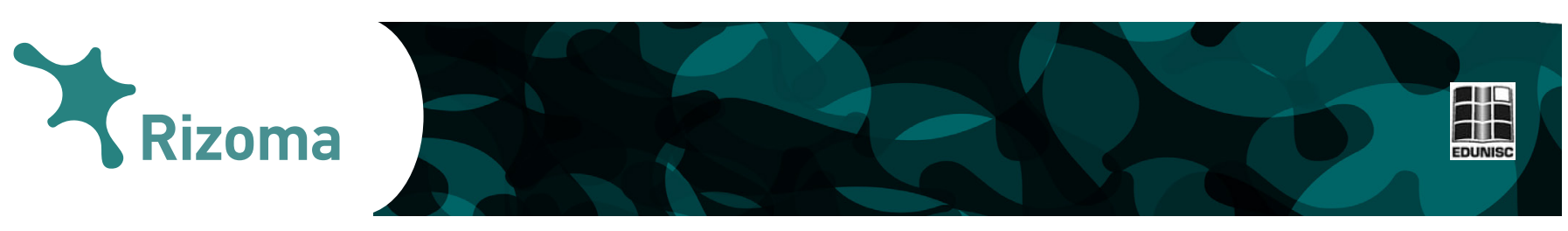

A família de Ilana, composta pelo pai, pela mãe e irmão (Arthur, Bobbie e Elliot), também participa do episódio para comemorar o seu $35^{\circ}$ aniversário de casamento, e esta é a história $C$. A maioria dos personagens secundários de Broad City está presente e as histórias deles se entrelaçam com a das protagonistas, mostrando a importância do personagem secundário para o desenvolvimento das narrativas. A cena final de Burning Bridges consiste em Abbi e Ilana conversando em uma banheira, Abbi confessa que estava gostando de Trey e as duas revelam segredos que nunca tinham contado uma a outra, demonstrando que a amizade delas nunca é abalada por nada.

Os roteiristas criaram uma terceira temporada mais profunda em relação às personagens e passamos a conhecer diferentes camadas de cada uma, observando aspectos de complexidade também para sitcons. Burning Bridges é um ótimo exemplo de como a série desenvolveu mais suas histórias e utiliza alguns recursos para prender o espectador. $\mathrm{O}$ episódio termina com vários ganchos de tensão e os fãs da série se questionam se Lincoln vai voltar atrás em sua decisão, como será o convívio de Trey e Abbi no trabalho, se Ilana arranjará um novo emprego, ou se irá se envolver com outra pessoa da mesma forma que se envolvera com Lincoln. Serão aspectos provavelmente explorados na quarta temporada.

\section{Enfim, aproximações e distanciamentos entre websérie e sitcom}

As séries televisivas vêm consolidando modelos inovadores de narrativa, ganhando em complexidade, segmentação e liberdade criativa, desde quando, ao afinal da década de 90, a HBO lançou a proposta de não ser TV, e começou a produzir dramas originais de uma hora de duração. Essa política arrojada de revolução criativa no circuito econômico das TVs por assinatura obviamente foi incorporada por outras plataformas e, nesse sentido, o consumo de séries, no intuito de legitimar estratégias de mercado, passou a se sustentar por "discursos de distinção" (CASTELLANO, 2016). Por outro lado, a plataforma Netflix "apesar de buscar distanciamento com relação às obras de televisão tradicional, acaba por reverenciar determinadas narrativas ao adicioná-las ao seu acervo" (CASTELLANO, 2016, p. 205). Tensões também são descritas entre a indústria cinematográfica, a televisão aberta e a cabo, o que normalmente envolve a busca por equilíbrio de forças entre estratégias de financiamentos e legitimidade artística (MARTIN, 2014).

Reflexões em torno das aproximações e rupturas em Broad City visam a, nesse artigo, apenas levantar proposições relevantes em torno da produção audiovisual. Partindo da ideia de superposição de novos arranjos para escrituras complexas, passa a ser fundamental a compreensão dessas possibilidades narrativas dos conteúdos televisivos, tanto convencionais como os expandidos para outros meios. Sendo assim, apontamos o primeiro aspecto curioso da análise, talvez a motivação central: Broad City migra da internet (espaço considerado livre e produtivo) para a televisão (restrito aos assinantes e mais 
suscetível a estratégias de controle). A websérie ao ser convertida em formato sitcom televisivo apodera-se de um modelo de negócios consolidado pelas verbas publicitárias, e que ainda atrai grande parte dos realizados, interessados por mais tecnologia, maior equipe de produção e consequente qualidade. Por outro lado, também observa-se uma mudança na lógica econômica dessas emissoras, para as quais o "sucesso" não é mais algo que exija um público massivo. "Uma vez que não existe um verdadeiro consenso do público em torno de nada [...] as histórias de qualidade, com novas vozes e ideias desafiadoras - marcas registradas da terceira Era de Ouro - talvez consigam resistir como outra categoria" (MARTIN, 2014, p. 354).

O trabalho aqui concluído, com foco na análise da estrutura narrativa de Broad City, pontuou aspectos da storyline central, algumas condições de produção e o processo de adaptação sofrido. Pela descrição do foco narrativo, da caracterização das personagens, das diversas formas de utilização do espaço, do tempo, e inevitavelmente os recursos estéticos empregados nas cenas, fotografia, figurinos e cenários, buscou-se perceber as relações e distanciamentos entre os dois universos narrativos. A partir deles, podemos concluir também que se o modelo comercial estabelecido pela TV parece mais seguro e atraente, entretanto, a rentabilidade na WEB se consolida por esse contato direto com os webespectadores, e pela possibilidade de incorporar experiências concretas com os fãs através dos canais de retorno próprios do espaço.

Fica evidente que as produtoras Abbi Jacobson e Ilana Glazer iniciaram seu processo de criação conduzidas pela estrutura que o próprio Youtube proporcionava, de uma audiência sem intermediários, a partir da qual as protagonistas passavam agregar dados coletados na própria vivência da atrizes. Aeraphe (2013) explica que é fundamental em uma websérie ter bons personagens que levem à identificação dos webespectadores com o seu mundo pessoal. Abbi e Ilana, quando produziram para a internet, tinham bastante autonomia na criação do produto e controle total sobre o que publicavam no seu canal. Uma estrutura curta - com começo, meio e fim - e formatada a partir de imagens mais intimistas - típicas dos formatos WEB - acabam sendo diferenciais para essa nova categoria de consumidores de vídeo, definida por Aeraphe (2013) como casual viewers, de atenção multitarefa, fragmentada e responsáveis por sua própria grade de programação, adequada às suas necessidades.

$\mathrm{Na} \mathrm{TV}$, informações como o sobrenome das protagonistas, onde elas moram, o que elas exercem no ambiente de trabalho, seus relacionamentos familiares e amorosos, tudo isto ganha destaque. Os personagens secundários exercem também um forte papel na sitcom, e não só contribuem para o desenvolvimento dos arcos narrativos das protagonistas, mas assumem suas próprias jornadas. As criadoras abusam dos relacionamentos entre os personagens, com mais conflitos, novas locações, histórias paralelas, easter eggs e ganchos de tensão em cada bloco, cativando o telespectador e mantendo-o motivado e fiel.

Para escrever um roteiro para websérie, Aeraphe (2013, p. 68) sugere antes de tudo pensar no público-alvo a ser contemplado, "através de temas onde há poucos personagens e locações a serem trabalhadas, concentrando a ação dramática e encurtando os arcos das tramas". Todavia, aconselha que 

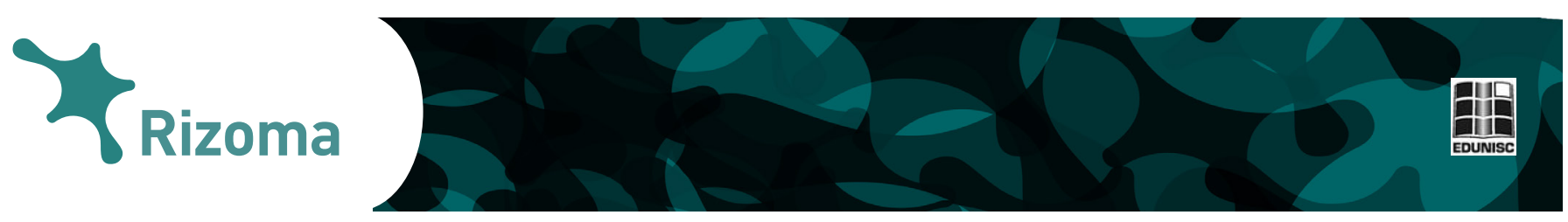

os realizadores superem o pensamento ultrapassado de que se é para internet pode ser feito de forma simplória e com baixa qualidade. Algumas dicas são: equipamentos de qualidade, equipe multidisciplinar, autossuficiente e o desenvolvimento de um modelo de negócio que transforme espectadores em divulgadores, ajudando assim a sanear financeiramente as produções.

O fato é que algumas influências destacadas na identidade do produto nos dois veículos possuem suas particularidades, algumas destas transitam livremente entre meios: da WEB -autonomia no processo criativo, foco nas personagens/ ações, imagens menos convencionais, ambientes mais intimista, entre outras; na TV - modelo de negócios estabelecido, narrativas mais complexas e qualidade de imagens.

\section{Autoprogramação das práticas de consumo: novas estratégias narrativas}

No decorrer deste trabalho, voltado a compreender possibilidades narrativas para o audiovisual contemporâneo, foram encontradas questões subjacentes para o entendimento de um cenário em transformação. Por assim dizer: quais propriedades têm poder de mobilizar nossa atenção na WEB e como realizadores em geral procuram se beneficiar disto?

Práticas ligadas ao consumo cada vez mais avesso ao modelo broadcasting são particularmente caracterizadas por aspectos bem específicos, entre eles: acesso a multiplataformas, sistemas de distribuição via streaming, disponibilidade ubíqua, consumo sob demanda, personalização, sistemas de recomendação, post-play, resume playback, além sobretudo da autonomia sobre o conteúdo, agora disponível a qualquer tempo via ações de bingewatching, ou seja, maratonas autoprogramadas. Massarolo e Mesquita (2017, p. 250) descrevem como estes comportamentos, factíveis através dos novos dispositivos de acesso e praticados pelos usuários, demonstram a autonomia do espectador e contribuem "para o surgimento de novas formas de consumo audiovisual, que se tornou personalizado e autoprogramado, acessível por diferentes plataformas". Os pesquisadores demonstram como a ação de "maratonar" fortalece estratégias de engajamento da cultura da participação, imersão dos espectadores nas narrativas e vínculos mais fortes com os produtos consumidos, ao consolidar sobremaneira os laços afetivos entre as partes.

São constatações como estas que configuram o audiovisual para além de questões técnicas ou simplesmente ligadas ao conteúdo em si, mas como ecologias complexas. Talvez por isso, seja cada vez mais conveniente ao estudarmos o campo não isolarmos os textos de seus contextos de produçãoe consumo, pois cada produto compõe uma rede intertextual para além dos limites da sua própria existência entre assistir e estar engajado no processo. Para Mittell (2015), a complexidade nesse contexto evidencia um conjunto distinto de normas de construção narrativa, que atravessa gêneros, processos criativos específicos e movimentos artísticos, para assim forjar uma categoria coerente e novos paradigmas. 

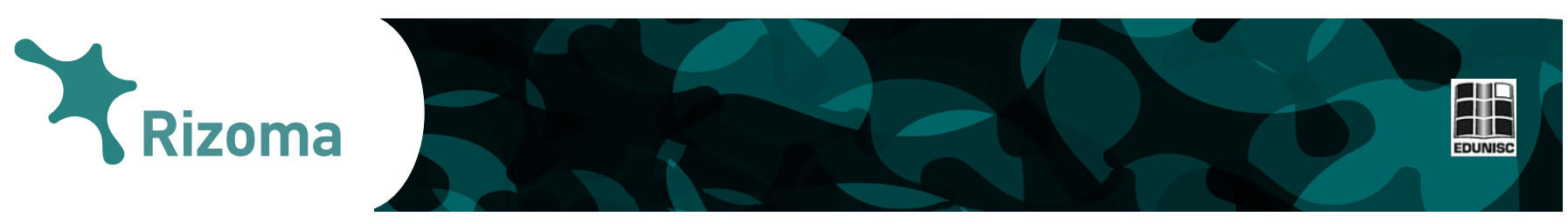

Em se tratando de narrativas seriadas, o atravessamento promovido entre TV e WEB já atribuem alterações nos formatos, cada vez mais complexos, híbridos, ao cruzar discursos ficcionais com aspectos da realidade. Correto talvez fosse afirmar que o seu objetivo estratégico seria criar identificação entre as partes envolvidas, no sentido de fidelizar a relação. No entanto, é inegável que também se estabeleçam vínculos emocionais e liberdade de escolha. $\mathrm{O}$ engajamento passa a considerar aspectos muito particulares do processo, pessoais e intransferíveis.

É claro que a fórmula para um produto audiovisual fazer sucesso é sempre um enigma inicial. Por outro lado, os dados levantados deixam evidentes aspectos de empatia, normalmente possível em segmentos de público, na articulação entre dramatização e referenciais de engajamento. Para os webespectadores é fundamental a "identificação com o seu mundo pessoal, real, e também com seu mundo imaginário" (AERAPHE, 2013, p. 50). No caso de Broad City, as situações expostas e a vivência com as personagens de forma tão intimista foram fundamentais para a série como um todo, inclusive para o segmento televisão, como nos confirma Jonah Weiner, em matéria ${ }^{5}$ sobre o Comedy Central, ao afirmar que a empresa, ao invés de grandes números de espectadores, valoriza encontrar públicos específicos e estimular a originalidade de suas produções para conseguir críticas positivas. Massarolo e Mesquita (2017, p. 249) sugerem que em ambiente multiplataforma e destinado a nichos específicos, a recepção muito provavelmente vai escolher ponderar acerca das diferentes formas de consumo, diferentes formatos, temas ou comportamentos: "sem as amarras de uma grade de programação fixa convencional e que obedece somente ao próprio ritmo de fruição".

Em conclusão, verifica-se que existem inúmeras maneiras de contar histórias e que essas histórias ativam seus "leitores" a partir de diferentes tipos de matérias e elaborações mentais da imagem - isso porque instituem paradigmas próprios de codificação, circunscritos em condições de produção e recepção diferenciados, nem sempre puros ou definitivos. No caso de Broad City, uma obra situada entre fronteiras, podemos perceber especificidades evidentes tanto da linguagem audiovisual para televisão, como de suas incorporações inevitáveis do formato exclusivo para a internet. A busca por detalhes dessa passagem pode trazer para o cenário midiático contemporâneo, percepções de novas histórias, mais densas e sofisticadas, assim como, o melhor envolvimento dos públicos e seus diferentes interesses.

\section{Referência}

AERAPHE, Guto. Webséries. Rio de Janeiro: Ciência Moderna, 2013.

Brasil. São Paulo: Iluminuras, 2007.

BOOTH, Paul. Digital fandom. Nova Iorque: Peter Lang, 2010.

5 Disponível no link: http://www.nytimes.com/2015/06/21/magazine/comedycentral-in-the-post-tv-era.html?_r=0. 

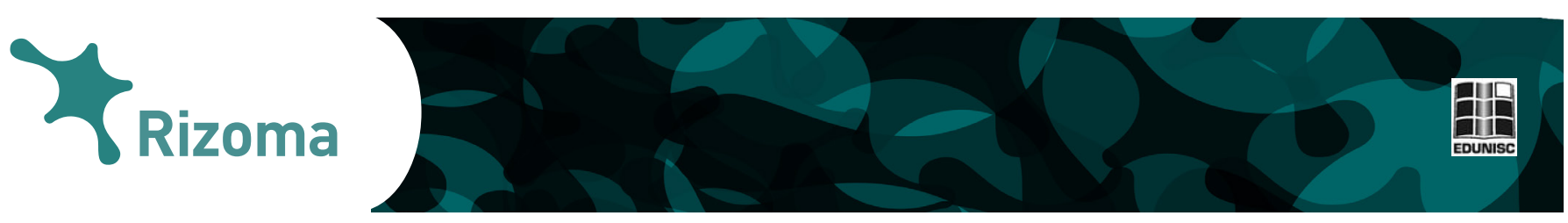

BULHÕES, Marcelo. A ficção nas mídias. São Paulo: Ática, 2009.

BROWN, Ross. Create your own TV series for the internet. Studio City, CA: Michael Wiese Productions, 2014.

CALABRESE, Omar. A idade neobarroca. São Paulo: Martins Fontes, 1987.

CASTELLANO, M.; MEIMARIDIS, M. Netflix, discursos de distinção e os novos modelos de produção televisiva. Revista Contemporânea, Salvador, v. 14, n. 2. p. 193-209, 2016.

GRECO, C.; HILLS, M. O fandom como objeto e os objetos do fandom. Matrizes, São Paulo, v. 9, n. 1, p. 147-163, 2015.

HILLS, Matt. Fan cultures. Londres: Routledge, 2002.

MACHADO, Arlindo. A televisão levada a sério. São Paulo: Senas, 2000. (Org). Arte e mídia. Rio de Janeiro: Jorge Zahar Ed, 2007.

MARTIN, Brett. Homens Difíceis. São Paulo: Aleph, 2014.

MASSAROLO, João. Práticas de binge-watching nas multiplataformas. In: LOPES, Maria Immacolata (Org). Por uma teoria de fãs da ficção televisiva brasileira II. Porto Alegre: Sulina, 2017.

MITTELL, Jason. Complex TV: The Poetics of Contemporary Television Storytelling. Nova Iorque: NY University Press, 2015.

PALLOTTINI, Renata. Dramaturgia de televisão. São Paulo: Perspectiva, 2012.

RODRIGUES, Sonia. Como escrever séries. São Paulo: Aleph, 2014.

SANTAELLA, Lucia. Matrizes da linguagem e pensamento. São Paulo: Iluminura, 2005.

SHIRKY, Clay. A cultura da participação. Rio de Janeiro: Zahar, 2011.

SIBILIA, Paula. O show do eu. RJ: Nova Fronteira, 2008.

ZANETTI, Daniela. Webséries. Revista Geminis, n.1. p. 69-88, 2013. 